\title{
Assessment of Nutritional Status between Children with Autism Spectrum Disorder and Normal Children of Bangladesh
}

Md. Ibrahim Sohel ${ }^{1 *}$

Md. Ashrafuzzaman ${ }^{2}$

Panchanan Acharjee ${ }^{3}$

Effat Zerin Epsi ${ }^{4}$

Hadi Md. Habib Ullah ${ }^{1}$

'Department of Anatomy

Chattogram Maa-O-Shishu Hospital Medical College Chattogram, Bangladesh.

${ }^{2}$ Department of Anatomy

Chittagong Medical College

Chattogram, Bangladesh.

${ }^{3}$ Department of Psychiatry

Chittagong Medical College

Chattogram, Bangladesh.

${ }^{4}$ Department of Anatomy

Mymensingh Medical College

Mymensingh, Bangladesh.

${ }^{*}$ Correspondence to:

Dr. Md. Ibrahim Sohel

Lecturer

Department of Anatomy

Chattogram Maa-O-Shishu Hospital Medical College

Chattogram, Bangladesh.

Mobile : +8801675085344

Email : jcsbiintpifm@gmail.com

Date of Submission : 12.04 .2021

Date of Acceptance : $\quad 16.05 .2021$

www.banglajol.info/index.php/CMOSHMCJ

\begin{abstract}
Background: Autism is one of the fastest spreading neuro-developmental disorders in the worldwide.Children with Autism spectrum disorder may be risk of suboptimal development which leads to increases morbidity, poor physical activity and performances.The aim of present study was to compare nutritional status between children with Autism spectrum disorder and normal children of Bangladesh.
\end{abstract}

Materials and methods: It was cross-sectional and observational study. The study population was Group A consists of 100 normal Bangladeshi children and Group B consists of 100 Bangladeshi children with Autism spectrum disorder, aged between 02 and 18 years collected by convenient sampling. Height, weight, triceps skin fold thickness, suprailiac skin fold thickness and Body Mass Index (BMI) were analyzed.

Results: Children with autism spectrum disorder had statistically significant lower height and weight; thicker triceps and suprailiac skin fold, were mostly under weight as compared to normal children.

Conclusion: The results of this study provide the baseline information about nutritional status of normal children and children with autism spectrum disorder in Bangladesh which will help to monitor nutritional growth of children.

Key words: Autism Spectrum Disorder (ASD); BMI; Bangladesh; Children; Triceps skin fold; Underweight.

\section{INTRODUCTION}

Autism is one of the fastest spreading neuro-developmental disorders in the worldwide, that affects social communication and normal behavior. Although it can be diagnosed at any age, but generally appear in the first two years of life ${ }^{1}$. Autism spectrum disorder occurs in all ethnic, racial and economic groups. Children with Autism spectrum disorder have varying of difficulties in social interaction, language and communication as well as normal behavior ${ }^{2}$.

The number of children diagnosed with Autism spectrum disorder has grown recently at what many call an alarming rate. The Centers for Disease Control and Prevention (CDC) estimated a 15 percent increase in autism prevalence among US children from 1 in 68 to 1 in 59 between 2014 and 2018. The Public Health Agency of Canada released the first national Autism spectrum disorder prevalence estimates among children aged 5-17 years for 2018. Their report estimates that 1 in 66 Canadian children and youth have an Autism spectrum disorder ${ }^{3}$.

The Autism spectrum disorder prevalence rate in Bangladesh is increasing gradually. However, there was no epidemiological such evidence on autism prevalence in rural Bangladesh. In the centre for Neurodevelopment \& Autism in Children, at Bangabandhu Sheikh Mujib Medical University data shown that higher rate of autism children at urban settings are seeking treatment from the facility. A national 
level study in Bangladesh during 2013 used community health worker, has found prevalence of Autism spectrum disorder; the study indicates a prevalence of $1.5 / 1000$ (30/1000 in Dhaka city and 7/10,000 in rural area) within 7200 population. In 2016, Institute of Paediatric Neurodisorder and Autism (IPNA) rural survey reported a figure of 7.5 per 10,000 children aged between 18 and 36 months ${ }^{4}$. The Daily Star published a report in 2018 mentioning that, according to a survey conducted by Dhaka Shishu Hospital in 2013, autism prevalence to be 15 per 10,000 children aged below nine ${ }^{5}$.

Body composition is strongly associated with nutritional status, specific diet, physical exercise, diseases and genes. The determination of body composition allows for the quantitative assessment of muscle mass and adiposity changes that reflects nutritional intake, losses and expenses over a time period. Determination of changing in body composition is very important in clinical investigation. Poor body composition and nutritional status can lead to increases morbidity, poor physical activity and performances. The growth, development and nutritional status of children can provide good information about the health of a community ${ }^{6}$.

A child grows in various ways like physical, mental, emotional, social and cultural growth ${ }^{7}$. Physical, mental and social developments are influenced by nutrition. The effect of under nutrition is related to retarded physical and mental growth. The direct effects of under nutrition are occurrence of sub clinical nutritional deficiency diseases. The indirect effects are high among young and growing children and leads to retarded physical and mental growth, lowered vitality leading to lowered productivity and reduced life expectancy, poor concentration and abnormal behaviour ${ }^{1,8}$. Children with Autism spectrum disorder may be risk of suboptimal development due to poor nutrition associated with restricted eating behavior, suppression of appetite or interfere of metabolism due to use of medication. So, measurement of anthropometric variables to examine the nutritional status of children with Autism spectrum disorder and to compare it with normal children will be helpful to assess general health condition and development of children with Autism spectrum disorder ${ }^{9}$. Children with under nutrition are not only at risk of morbidity and mortality but also likely to perform poorly in their academic activities ${ }^{10}$. Several studies on anthropometric variables of children with Autism spectrum disorder in different racial origins were reported, but there is no such report yet on the Bangladesh. To serve this purpose, the present study was designed to compare nutritional status between children with Autism spectrum disorder and normal children of Bangladesh.

\section{MATERIALS AND METHODS}

It was cross-sectional and observational study with some analytical components, carried out in the Department of Anatomy, Chittagong Medical College, Chattogram, during the study period of July, 2018 to June, 2019. The study population was divided into two groups. Group A was 100 normal Bangladeshi children and Group B was 100 Bangladeshi children with Autism spectrum disorder aged between 02 and 18 years collected by convenient sampling. Those having any skeletal disease/deformity were excluded from the study. Ethical clearance for doing the research was obtained from the Institutional Review Board /Ethical Review Board (E.R.B) of Chittagong medical College.

Five variables namely height, weight, triceps skin fold thickness, suprailiac skin fold thickness and Body Mass Index (BMI) were analyzed in this study.

\section{Operational Definitions}

Height: Height or stature is the measurement of vertical distance from the top of the head (The vertex) to the floor ${ }^{11}$.

Weight: A body's relative mass or the quantity of matter contained by it, giving rise to a downward force, the heaviness of a person or thing ${ }^{12}$.

Triceps skin fold thickness: It is the width of a fold of skin taken over the triceps muscle ${ }^{12}$

Suprailiac skin fold thickness: It measures skin fold thickness just above the iliac crest $^{12}$.

BMI: BMI is a person's weight in kilograms $(\mathrm{Kg})$ divided by his or her height in meter squared ${ }^{12}$.

Before going into the procedure upon the study subjects, parents, teachers or legal guardian of each subject were informed about the nature of the study and informed written consent was obtained. A checklist was designed by the researcher to collect information regarding age, sex, parental heritage and the information supporting the inclusion and exclusion criteria. Subject's parents or teachers were requested to help in positioning their children. All dimensions of every individual were measured by the same observer, with the same instrument to avoid any technical and/or interobserver error ${ }^{13}$. In this study each participant was measured twice for each dimension and the average value of the two measurements was taken, as the true value of the participant ${ }^{14}$. A third reading was taken, if the initial two measurements greatly differed and the two closer readings would then be used.

The participant's parents/teachers were asked to stand their children on barefooted heel together, toes apart and back as straight as possible. The participant's head was positioned in the Frankfort horizontal plane. A steel plate was placed against the head and wall, and this was marked by black eye pencil. The participant was then stepped away from the wall. The stature was then measured from the floor to the marked point on the wall with a measuring steel tape ${ }^{12}$.The weight of the children was recorded with wearing minimum clothing and bare feet using a portable digital weighting machine to the nearest 0.1 gram $^{6}$. To measure triceps skin fold thickness, a fold of skin and subcutaneous adipose tissue was grasped gently by the observer with thumb and fingers approximately $2.0 \mathrm{~cm}$ above the mid point of triceps with the skin fold parallel to the long 
axis of the arm. The Harpenden skin fold calipers were placed per pendicular to the length of the fold and the skin fold thickness was measured to the nearest $0.1 \mathrm{~mm}$ while the fingers continue to hold the skin fold ${ }^{12}$. To measure suprailiac skin fold thickness, the right hip area of the participant was exposed. The observer placed his thumb (Left) on the highest point of iliac crest and picked up the skin fold with the thumb and fingers. The skin fold was sloped downward and forward at a 45-degree angle extending toward the pubic symphysis. The Harpenden skin fold calipers was placed per pendicular to the skin fold about $2.0 \mathrm{~cm}$ medial to the fingers and the skin fold was measured to the nearest $0.1 \mathrm{~mm}^{12}$.

The range, mean and standard deviation of values of the variables were calculated using computer-based programs Statistical Package for Social Science (SPSS version-22). Unpaired Student's ' $t$ ' test was done.

\section{RESULTS}

Table I showed the demographic characteristics of the participants. The mean age of the participants was $11.81 \pm 2.71$ years in Group A and 8.95 \pm 3.94 years in Group B. Out of 200 subjects, $147(73.5 \%)$ were male and $53(26.5 \%)$ were female.

Table I : Demographic characteristic of the participants

\begin{tabular}{|c|c|c|c|}
\hline \multirow[t]{2}{*}{ Variable } & \multicolumn{2}{|c|}{ Group } & \multirow[b]{2}{*}{ Total } \\
\hline & $\begin{array}{l}\text { Normal Children } \\
\text { (Group A) } \\
(\mathrm{n}=100)\end{array}$ & $\begin{array}{l}\text { Children with } \\
\text { Autism spectrum } \\
\text { disorder (Group B) } \\
\quad(\mathrm{n}=100)\end{array}$ & \\
\hline \multicolumn{4}{|c|}{ Age (In years) } \\
\hline Range & $4-17$ & $3-18$ & $3-18$ \\
\hline Mean \pm SD & $11.81 \pm 2.71$ & $8.95 \pm 3.94$ & $10.38 \pm 3.33$ \\
\hline \multicolumn{4}{|l|}{ Gender } \\
\hline Male & 71 & 76 & 147 \\
\hline Female & 29 & 24 & 53 \\
\hline
\end{tabular}

Comparisons of height, weight, triceps skin fold thickness and supra iliac skin fold thickness between normal children and children with Autism spectrum disorder.

Table 2 shows that the mean height of normal children (1.42 meters) was comparatively more than that of children with autism spectrum disorder (1.26 meters) and it was statistically very highly significant $(t=6.23, \mathrm{p}<0.001)$. The mean weight of normal children was $39.65 \mathrm{~kg}$ and that of children with autism spectrum disorder was $30.77 \mathrm{~kg}$. The difference was very highly significant $(\mathrm{t}=4.19, \mathrm{p}<0.001)$ where normal children were having significantly more weight than children with autism spectrum disorder (Table II). Table II shows that Children with Autism spectrum disorder have a very highly significant thicker skin fold for both triceps $(\mathrm{t}=-3.97, \mathrm{p}<0.001)$ and supra iliac skin fold $(\mathrm{t}=-4.7, \mathrm{p}<0.001)$ than normal children.
Table II : Comparison of Height, Weight, triceps skin fold thickness and supra iliac skin fold thickness between normal children and children with Autism spectrum disorder

\begin{tabular}{|c|c|c|c|}
\hline Variables & $\begin{array}{l}\text { Normal children } \\
\text { (Group A) } \\
\text { Mean } \pm \text { SD } \\
(\mathbf{n}=\mathbf{1 0 0 )}\end{array}$ & $\begin{array}{l}\text { Children with } \\
\text { Autism spectrum } \\
\text { disorder } \\
\text { (Group B) } \\
\text { Mean } \pm \text { SD } \\
(\mathrm{n}=100)\end{array}$ & $p$ value \\
\hline Height & $1.42 \pm 0.17$ & $1.26 \pm 0.20$ & $<0.001 * * *$ \\
\hline Weight & $39.65 \pm 12.01$ & $30.77 \pm 17.47$ & $<0.001 * * *$ \\
\hline Triceps skin fold & $8.98 \pm 3.81$ & $11.71 \pm 5.72$ & $<0.001 * * *$ \\
\hline Supra iliac skin fold & $7.02 \pm 4.15$ & $10.72 \pm 6.70$ & $<0.001 * * *$ \\
\hline
\end{tabular}

****ery highly significant.

Comparison of BMI between normal children and children with Autism spectrum disorder.

The average BMI for normal children was 19.30 and that for children with autism spectrum disorder was 18.29. Table III display that Children with autism spectrum disorder were mostly underweight as compared to normal children.

Table III : Comparison of BMI with the two groups of respondents

\begin{tabular}{lccr} 
BMI classification & \multicolumn{2}{c}{$\begin{array}{c}\text { Group of respondents } \\
\text { Normal children } \\
\text { (Group A) }\end{array}$} & $\begin{array}{c}\text { Children with } \\
\text { autism spectrum } \\
\text { disorder (Group B) }\end{array}$ \\
\\
Under weight $(<18.5)$ & 23 & 67 & 90 \\
Healthy weight $(18.5-24.9)$ & 71 & 24 & 95 \\
Overweight $(25-29.9)$ & 4 & 3 & 7 \\
Obese 30 or $>30$ & 2 & 6 & 8 \\
Total & 100 & 100 & 200 \\
\hline
\end{tabular}

\section{DISCUSSION}

Autism spectrum disorder is one of the commonest neurodevelopmental disorders in Bangladesh. It is diagnosed using DSM 5 criteria $^{2}$. Although these criteria are useful for final confirmation, examination of the anthropometric variables by physical procedure will be also useful technique in the clinical assessment.

During selection of the participants, the age limit was a very important factor. In present study, preferred lower limit of age is 2 years because children with Autism spectrum disorder are diagnosed at the age of 2 years. The preferred higher limit of age is 18 years, because up to 18 years the human being is considered as children ${ }^{15}$.

Autism spectrum disorder is almost 5 times more common in male children than female children ${ }^{16}$. Since the study was done by convenient sampling, any case that matched the inclusion criteria was added as study subject after obtaining permission from their parents/guardians. In the present study (Table I) 76 
males and 24 females were diagnosed cases of Autism spectrum disorder, the male and female ratio in Bangladeshi children with Autism spectrum disorder was 2.8:1. Hofvender et al reported male and female ratio of Autism spectrum disorder was 2 to $2.4: 1^{17}$. Jensen et al studied ASD incidence rates across the lifespan and identified a reduction of male and female ratio from 5:1 to 3:1 between 1995 and $2010^{18}$. So, it is suggested that the number of males affected by autism spectrum disorder is more than that of the number of females affected by this condition. The exact cause of the gender imbalance of Autism spectrum disorder is unknown.

As shown in Table II, children with autism spectrum disorder appeared to be shorter than normal children \& it was statistically very highly significant. Mari-Bauset et al also reported, children with ASD in Spain is shorter than normal children ${ }^{9}$. Another study done by Liu et al in China, where height was found to be significantly lower in the children with ASD compared with normal children ${ }^{19}$. Contrary to this finding, it has been observed in several studies that children with ASD had normal heights when matched for age and gender with normal children and Meguid et al showed autistic children to be significantly taller than normal children ${ }^{20-22,8}$.

When weight was concerned, on Table II, children with Autism spectrum disorder were significantly underweight when compared with normal children (t- 4.19, $\mathrm{p}<0.001$ ). Srivastava et al reported that Children with ASD compared with normal children found to be underweight in India ${ }^{1}$. Another study carried out on Oman by Al-Farsi et al reported that ASD children age three to five years showed a prevalence of malnutrition ${ }^{23}$. The most common type of malnutrition was underweight, followed by wasting and stunting. Mari-Bauset et al also found in Spanish ASD children were underweight when compared to healthy children ${ }^{9}$. Although, multiple studies have concluded that there is no significant difference in weight patterns between normal children and children with $\mathrm{ASD}^{21,24,25}$. In this study, children with ASD were found to have significantly thicker triceps skin fold and supra iliac skin fold (Table II). Meguid et al reported that triceps and supra iliac skin fold thicknesses are significantly thicker in autism children than in normal children ${ }^{8}$. Berry et al also reported that triceps and supra iliac skin fold thickness is more in Autism children than normal children ${ }^{26}$. The probable cause is typically children with autism spectrum disorders have strong preference for carbohydrates and rejection to fruits, vegetables and dairy products, which indicate the increase of fat component and subsequent deposition of fat $^{8,26}$.
In the present study, $67 \%$ of children with Autism spectrum disorder were underweight and 24\% were healthy weight, $71 \%$ of normal children were healthy and $23 \%$ were underweight (Table III) and it was statistically very highly significant $(p<0.0001)$. Mari-Bauset et al. categorized the children with Autism spectrum disorder by BMI as underweight, healthy, overweight or obese and reported that Autism spectrum disorder children became more distorted than normal children with higher number of cases in the two extremes either underweight or obese ${ }^{16}$. Al-Farsi et al and Mar -Bauset et al found higher underweight rates in children with ASD than in typically developing children ${ }^{23,9}$. Srivastava et al reported that BMI distribution in children with ASD in India was less \& underweight when compared to normal children and the result was highly significant ${ }^{1}$. Possible explanations for underweight ASD children were hyperactivity, abnormal behavior leading to stress, or other comorbidities such as gastrointestinal diseases, lack of appetite, or even genetic factors ${ }^{27}$. Another study done in Morocco, found children with ASD to be more fussy eaters and significantly more malnourished than normal children ${ }^{28}$. Nevertheless, several studies have also found, high rates of obesity in children with $\mathrm{ASD}^{29,30}$. In this study only $6 \%$ children with $\mathrm{Au}-$ tism spectrum disorder were obese.

\section{CONCLUSIONS}

This study showed that the Bangladeshi Children with autism spectrum disorder had statistically significant lower height and weight; thicker triceps and suprailiac skin fold; and were mostly underweight as compared to normal children. The results of this study provide the baseline information about nutritional status of normal children and children with autism spectrum disorder in Bangladesh which will help to monitor nutritional growth of children.

\section{DISCLOSURE}

All the authors declared no competing interest. 


\section{REFERENCES}

1. Srivastava K, Raman M. Bhattacharya A.A study on comparison of anthropometrics of autism spectrum disorder with normal children. IJIRT. 2016; 5(6): 484-487.

2. Khalifeh S, Yassin W, Kourtian S. Boustany RM. Autism in review. J Med Liban. 2016;64(2):110-115.

3. Ofner M, Coles A, Decou ML, Do M, Bienek A. Snider J et al. Autism Spectrum Disorder among children and youth in Canada. Public Health Agency of Canada. 2018.

4. Akhter S, Hussain E, Shefa J, Kundu GK, Rahman F, Biswas A.Prevalence of Autism Spectrum Disorder (ASD) among the children aged 18 36 months in a rural community of Bangladesh: A cross sectional study. F1000 Research. 2018;1(7).

5. Molla MA. Autism prevalence high in urban areas. The Daily star. retrieved 10 Jan 2019.

Available from:https://www.thedailystar.net/frontpage/autism-prevalence-high-urban-areas-1604551.

6. Sen J, Mondal N, Ghosh P.Upper Arm Composition as an Indicator of Body Composition and Nutritional Status of Adolescent Boys Aged 1018 Years. Journal of Nepal Paediatric Society. 2015;35(2).

7. Mohammadi MR. A comprehensive book on autism spectrum disorders.ed. Demand,JanezaTrdine 9. 51000 Rijeka: Croatia. 2011.

8. Meguid NA, Kandeel WA, Wakeel KE, El-Nofely AA.Anthropometric assessment of a Middle Eastern group of autistic children. World J Pediatr. 2014;10(4):318-323.

9. Mari-Bauset SM, Zazpe I, Sanchis AM, González AL, Suárez-Varela MM. Are there anthropometric differences between autistic and healthy children? J Child Neurol. 2013;28(10):1226-1232.

10. Senbanjo IO, Oshikoya KA, Njokanma OF.Upper arm composition and nutritional status of school children and adolescents in Abeokuta, Southwest Nigeria. World J Pediatr. 2014;10(4):336-342.

11. Hossain S, Begum JA, Akhter Z. Measurement of Stature from Arm-span An Anthropometric Study on Garo Tribal Bangladeshi Females. BJA. 2011;9(1)5-9.

12. Center for Disease Control and Prevention. National Health and Nutrition Examination Survey. Research Boulevard, Rockville. $2007 ; 1650$.

13. El-Din SM, Elkholy S, Yousef MI.Prediction of stature based on upper limb measurements among Egyptian population. Eur J Forensic Sci. 2016;3,(2):1. doi: 105455/ejfs. 191463.

14. Hossain S.An anthropometric study of upper limb dimensions as related to stature and determination of frame index and palm index in christian Garo adult females. master thesis, Bangabandhu Sheikh Mujib Medical University. Dhaka. 2009.

15. World Health Organization. Promoting rights and community living for children with psychosocial disabilities. 2015. Retrieved 1 Dec 2018. Available from:http://www.who.int.

16. Marí-Bauset S, Llopis-González A, Zazpe I, Mari-Sanchis A, Morales-Suárez-Varela M.Anthropometric measures of Spanish children with autism spectrum disorder. Res Autism SpectrDisord. 2015;9:26-33.

17. Hofvander B, Delorme R, Chaste P, Nydén A, Wentz E, Ståhlberg O, Herbrecht E et. al.Psychiatric and psychosocial problems in adults with normal-intelligence autism spectrum disorders. BMC psychiatry. 2009;9(1):35.

18. Jensen CM, Steinhausen HC, Lauritsen MB. Time trends over 16 years in incidence-rates of autism spectrum disorders across the lifespan based on nationwide Danish register data. J Autism DevDisord. 2014;44(8):1808-1818. doi: https://doi.org/10.1007/s10803-014-2053-6.

19. Liu X, Liu J, Xiong X, Yang T, Hou N, Liang X, et al.Correlation between Nutrition and Symptoms: Nutritional Survey of Children with Autism Spectrum Disorder in Chongqing, China. Nutrients. 2016;8(9):294. doi:10.3390/nu8050294.

20. Lainhart JE, Bigler ED, Bocian M, Coon H, Dinh E, Dawson G, et al.Head circumference and height in autism. A study by the collaborative program of excellence in autism. Am J Med Genet A.2006;140:2257-2274.

21. Emond A, Emmett P, Steer C, Golding J.Feeding symptoms, dietary patterns, and growth in young children with autism spectrum disorders Pediatrics. 2010;126(2);337-342.

22. Mills JL,Hediger ML, Molloy CA, Chrousos GP, Manning Courtney P, Yu KF. Elevated levels of growth related hormones in autism and autism spectrum disorder. Clinical endocrinology. 2007;67(2):230-237.

23. Al-Farsi YM, Al-Sharbati MM, Waly MI, Al-Farsi OA, Al Shafaee MA, Deth RC. Malnutrition among preschool-aged autistic children in Oman. Research in Autism Spectrum Disorders. 2011;5(4):1549-1552. doi:10.1016/j.rasd.2011.02.018

24. Evans EW, Must A, Anderson SE., Curtin C, Scampini R, Maslin M, et al.Dietary patterns and body mass index in children with autism and typically developing children. Research in Autism Spectrum Disorders. 2012;6(1):399-405.

25. Herndon AC, Di Guiseppi C, Johnson SL, Leiferman J, Reynolds A.Does nutritional intake differ between children with autism spectrum disorders and children with typical development? J Autism DevDisord.2009;39:212-222.

26. Berry R, Sharp WG, Jaquess DL, Hartwig S.Food selectivity and autism: a retrospective chart review regarding the anthropometric status, nutritional intake and dietary variety among children with and without ASD. Pub Marcus Autism Center. 2012.

27. Bolte S, Ozkara N, Poutska F.Autism spectrum disorders and low body weight: Is there really a systematic association? Int J Eat Disord. 2002;31:349-351.

28. Hafid A, Touhamiahami AO.Autistic Children Food Habits and the Risk of Running Malnutrition in Morocco. Asian J. Epidemiol. 2018;11:8-13.

29. Bicer AH, Alsaffar AA.Body mass index, dietary intake and feeding problems of Turkish children with autism spectrum disorder (ASD). Res DevDisabil. 2013;34(11):3978.

30. Xia W, Zhou Y, Sun C, Wang J, Wu L.A preliminary study on nutritional status and intake in Chinese children with autism. Eur J Pediatr. 2010;169(10):1201-1206. 